\title{
Identification of Plant Growth Promoting Bacteria Within Space Crop Production Systems
}

\author{
David Handy ${ }^{1}$, Mary E. Hummerick ${ }^{2}$, Anirudha R. Dixit ${ }^{2}$, Anna Maria Ruby $^{3}$, Gioia Massa ${ }^{3}$ and \\ Andrew Palmer ${ }^{1,4,5 *}$ \\ ${ }^{1}$ NASA Internships Intern, Kennedy Space Center, Melbourne, FL, United States, ${ }^{2}$ Amentum/LASSO, Kennedy Space Center, \\ Merritt Island, FL, United States, ${ }^{3}$ Utilization and Life Sciences (UB-A), Kennedy Space Center, Merritt Island, FL, United States, \\ ${ }^{4}$ Department of Biomedical and Chemical Engineering and Science, Florida Institute of Technology, Melbourne, FL, United States, \\ ${ }^{5}$ Aldrin Space Institute, Florida Institute of Technology, Melbourne, FL, United States
}

OPEN ACCESS

Edited by:

Cyprien Verseux

University of Bremen, Germany

Reviewed by:

Henry Sun,

Desert Research Institute (DRI),

United States

Oleg Reva,

University of Pretoria, South Africa

*Correspondence: Andrew Palmer

Apalmer@fit.edu

Specialty section: This article was submitted to

Astrobiology,

a section of the journal Frontiers in Astronomy and Space

Sciences

Received: 03 July 2021 Accepted: 30 September 2021 Published: 19 October 2021

Citation: Handy $D$, Hummerick ME, Dixit $A R$, Ruby AM, Massa $G$ and Palmer $A$ (2021) Identification of Plant Growth Promoting Bacteria Within Space Crop Production Systems.

Front. Astron. Space Sci. 8:735834. doi: 10.3389/fspas.2021.735834
As we establish colonies beyond Earth, resupply missions will become increasingly difficult, logistically speaking, and less frequent. As a result, the on-site production of plants will be mission critical for both food production as well as complementing life support systems. Previous research on space crop production aboard the International Space Station (ISS) has determined that the spaceflight environment, though capable of supporting plant growth, is inherently stressful to plants. The combined stressors of this environment limits yield by inhibiting growth, as well as increasing susceptibility to infection by plant pathogens such as Fusarium spp. We propose that a consortium of space-viable, plant growth-promoting bacteria (PGPB) could assist in mitigating challenges to plant growth in a sustainable fashion. Here, we utilize biochemical and phenotypic assessments to identify potential PGPB derived from previously acquired isolates from the VEGGIE crop production system aboard the ISS. These assays confirmed the presence of bacteria capable of producing and/or interfering with plant hormones, facilitating plant uptake of high-value target nutrients for plants such as iron and phosphorus, and able to inhibit the growth of problematic fungal species. We discuss our findings with regards to their potential to support plant growth aboard spaceflight platforms as well as the Moon and Mars.

Keywords: regenerative life support, plant growth promoting (PGP) bacteria, space agriculture, astrobiology, space crop production

\section{INTRODUCTION}

To ensure the longevity of human space colonization it is imperative to develop safe and sustainable methods of life support on the surface of a planetary body, as well as on deep space transports. Bioregenerative life support systems (BLSS) use biological processes to support a human crew by recycling air and water, and in more advanced systems provide food. Food production is an extremely important aspect of BLSS for deep space missions such as establishing a Mars colony. As humanity establishes colonies further from Earth the logistics of resupply missions will become increasingly complicated, limiting their frequency. Relying on resupply missions to provide food for an off-world colony will not only be infeasible, but failed or delayed resupplies would be detrimental, potentially lethal, to colonists. 
Current food production systems in space are limited to modified hydroponic systems in microgravity such as the Veggie growth system or the Advanced Plant Habitat aboard the International Space Station (ISS). Crop selection for these systems focuses on relatively fast-growing, pick-and-eat foods (i.e., selections that require no processing/cooking to be eaten) that can supplement the astronaut diet. These selections provide nutrition lacking in prepackaged food such as potassium, or may not be stable over long duration missions, such as vitamin $\mathrm{C}$ (Cooper, 2013), but are not a significant source of caloric intake. Food production systems for the Moon and Mars will likely have the same considerations for early phase crop selection, retaining these nutritious accessory crops, while also moving toward the production of staple crops with higher caloric density.

The other benefit of these systems that has been noted is a psychological benefit, both to eating fresh food, and tending to the plants (Odeh and Guy, 2017). These benefits to the emotional and psychological health of crew members have been reported not only in space, but in the Neumayer Station in Antarctica (Mauerer et al., 2016). These findings underscore the importance that plant growth systems will play in overall crew health in deep space missions, as well as on colonies on the Moon and Mars.

The Veggie system is a modified hydroponic plant growth system that uses a "root pillow" containing an arcillite growth substrate which helps to carry water and suspended nutrients to the roots in microgravity (Massa et al., 2017a). Initial flight tests of the Veggie system, supported that the average fresh mass of surviving plants was higher in space flight samples compared to ground controls, albeit with large variability. However, the total number of ground control plants which survived over the duration of the study was significantly higher than those in microgravity (Massa et al., 2017a). Many of the plants in the flight system exhibited guttation, stunted growth, leaf curling, and chlorosis, all hallmarks of different stress responses, and ultimately resulted in the death of many of these plants. One of the major sources of stress in these systems is the behavior of water in the microgravity environment which can limit nutrient uptake, suffocate roots, and allow potentially pathogenic microorganisms, such as fungi, better access to host tissues as water builds up on leaves and around roots (Massa et al., 2017a). Strategies to improve plant growth, relieve stress, and improve disease resistance are in high demand for these environments.

On Earth, plants are assisted by a multitude of microorganisms, generically classified as plant growthpromoting bacteria (PGPB) which provide a variety of functions to their hosts, typically in exchange for a variety of carbon sources contained within root exudates. These include functions such as: 1) the production and manipulation of plant growth hormones (Ludwig-Müller, 2015), 2) interference of ethylene production by deamination of 1-aminocyclopropane-1-carboxylate (ACC) (Gamalero and Glick, 2015), 3) fixation of atmospheric nitrogen (Franche et al., 2009), 4) scavenging nutrients from the environment (Rodríguez et al., 2006; Scavino and Pedraza, 2013), or 5) provide resistance to potential pathogens (Compant et al., 2005). We propose that PGPB could perform a similar function aboard the ISS and other off- world sites to ameliorate the stressors associated with these environments.

In order to be sustainable, colonies on the Moon and other planets will need to practice in situ resource utilization (ISRU), or using resources available at the site of the colony to ensure sustainable operations. ISRU efforts toward food production often look at using the regolith available on site as a plant growth substrate, though studies using regolith simulants have shown the need for applied fertilizers (Bugbee and Salisbury, 2015; Eichler et al., 2021). Bacteria capable of scavenging nutrients from regolith, or simply facilitating nutrient uptake from fertilizer solutions would reduce the demand for those nutrients from Earth. Many PGPB can solubilize the key nutrient, phosphate, which may be present in regolith minerals, or may precipitate out of solution when interacting with other geologic material such as calcium, iron, or aluminum (Rodríguez et al., 2006; Ambrosini and Passaglia, 2017).

The general potential for PGPB to limit the growth of potential pathogens, either by producing antimicrobials or through effective competition, is of great interest for future BLSS (Compant et al., 2005), as it has been proven difficult to completely eradicate potential plant pathogens on the ISS via sterilization and sanitization. Some PGPB bacteria can produce organic compounds known as siderophores as biocontrol agents for potential pathogens. These compounds frequently work by chelating iron and there is wide diversity among siderophores produced by different organisms, along with a variety of transport proteins. This allows an organism to compete for resources by making the nutrient unavailable to competitors (Scavino and Pedraza, 2013). Such siderophores may also have the potential to scavenge iron from the rich iron-oxide deposits in Martian regolith making this crucial nutrient more available to plants in this environment (Blake et al., 2013).

While the biological control of potential pathogens is an important role for $\mathrm{PGPB}$, the most common functions of PGPB are those that improve overall plant growth. One common mechanism for improving plant growth is through manipulation of plant hormones, such as the production of indole-3-acetic acid (IAA), or the interference of ethylene production. IAA is the most common form of auxin, the plant growth hormone. Stimulating auxin responses can encourage root and shoot elongation in most plants, while facilitating nodulation in legumes (Ludwig-Müller, 2015). Ethylene is a volatile hormone commonly used by plants in abiotic stress responses, as well as in defense against pathogens, and is associated with a reduction in overall growth. Some PGPB, as well as some pathogens, can inhibit ethylene production by metabolizing the ethylene precursor 1-Aminocyclopropane-1carboxylic acid (ACC) as a nitrogen source. This allows the plant to become more resistant to abiotic stress, by ignoring these effects at low concentrations. Reduced ethylene production is frequently associated with increased plant growth and nodulation given the inhibitory effect this hormone can have on auxin responses (Gamalero and Glick, 2015). In summary, there are a variety of ways in which PGPB may ameliorate the challenges plants face in both the spaceflight environment as well as on an off-world colony. 
However, for the protection of the crews who work with the plants, just like all the other items sent to space, everything in these systems are either sterilized or sanitized in the case of the seeds used (Massa et al., 2017b), and these practices are likely to continue. Yet despite these efforts to remove microbes from these systems, the ISS has a fairly diverse microbiome both in the plant growth systems (Khodadad et al., 2020), and on the general space station surfaces (Checinska Sielaff et al., 2019). The microbiome on the ISS is predominantly derived from the human microbiome (Avila-Herrera et al., 2020), which is then spread to the plants via astronauts during watering, pruning, and multi-round harvesting.

Seed-borne endophytic microbes which were unaffected by the surface sanitization of the seeds are likely to contribute to the plant microbiome as well (Ravel et al., 1997; Pitzschke, 2016). It is from this group of seed-borne endophytes that there may be a subset of plant growth promoting bacteria (PGPB) growing in the plant growth systems of the ISS. Yet, bacterial populations in Veggie are fairly heterogenous between various flight experiments, and while certain genera are consistently present, there are seemingly random differences in their distributions (Khodadad et al., 2020). It is therefore prudent to consider the development of a curated microbiome enriched with specific PGPB with which seeds could be inoculated.

The routine use of such a PGPB "probiotic" can improve current and future space food production systems, enhancing the sustainability of these systems on the Moon and Mars. We hypothesized that previous isolates from the Veggie system, were an ideal starting point for the identification of potential PGPB as they already have spaceflight history, indicating their ability to survive the launch process as well as grow in the spaceflight environment. (Khodadad et al., 2020). These bacterial isolates from the Veggie production system aboard the ISS were provided by NASA Kennedy Space Center (KSC) for study and a subset were screened for the presence of PGPB. Specifically, we have investigated these microorganisms for potential PGP functions including siderophore production, phosphate solubilization, indole production, ACC deaminase activity, and fungal growth inhibition. Our efforts confirm the existence of multiple PGPB strains as candidates for further study for their ability to improve yield and reduce stress on plants aboard the ISS. We discuss our findings in the context of their short-term benefits aboard the ISS along with the long-term potential to the development of bioregenerative life support systems in off-world sites.

\section{MATERIALS AND METHODS}

\section{Maintenance of International Space Station Isolates}

Parameters of the Veggie system are described in (Massa et al., 2017a). The isolation and identification of the bacterial and fungal species used in this study were previously reported as well (Khodadad et al., 2020). From this study a subset of bacteria and fungi were selected for their evaluation as PGPB. Bacterial species used in the present study include: Acinetobacter genomospecies 3, Bacillus altitudinis, Bacillus amyloliquefaciens, Bacillus pseudomycoides, Bacillus pumilus, Bacillus subtilis, Burkholderia pyrocinnia, Cupriavidus pauculus, Curtobacterium flaccumfaciens, Curtobacterium pusillum, Leifsonia aquatica, Methylobacterium rhodinium, Microbacterium marytipicum, Paenibacillus macerans, Paenibacillus pabuli, Pantoea agglomerans, Paracoccus yeeii, Pseudomonas fulva, Ralstonia picketii, Sphingobacterium multivorum, and Stenotrophomonas rhizophila. Fungal species used in this study include: Fusarium anthophilum, Aspergillus sydowii, Aspergillus ustus, and Emericella parvathecia.

Bacterial samples were taken from freezer stocks made using $30 \%$ glycerol media maintained at $-80^{\circ} \mathrm{C}$. Fresh cultures were maintained on $1.5 \%$ solid agar King B media, containing $1.5 \%(\mathrm{v} /$ v) glycerol, $20 \mathrm{~g} / \mathrm{L}$ peptone, $1.15 \mathrm{~g} / \mathrm{L} \mathrm{K}_{2} \mathrm{HPO}_{4}$, and $1.50 \mathrm{~g} / \mathrm{L}$ $\mathrm{MgSO}_{4} .7 \mathrm{H}_{2} \mathrm{O}$. Fungal samples were maintained on Inhibitory Mold Agar (IMA) (BBL, Difco, Beckton Dickenson, Franklin Lakes, NJ). All isolates used were cultured from microbial screens of Veggie system flight samples. Stocks were streaked every 2 weeks to maintain fresh cultures.

\section{Siderophore Production}

Methods for detection of bacterial siderophores were adapted from Ambrosini and Passaglia (2017). Chrome azurol S dye solution (CAS) was made by combining, an iron (III) chloride solution, a chrome azurol S solution, and cetrimonium bromide solution were combined with a piperazine/ $\mathrm{HCl}$ buffer, filter sterilized, then added to $0.2 \mathrm{X}$ King B molten agar in a $100 \mathrm{ml} /$ $\mathrm{L}$ ratio.

21 Bacterial isolates were cultured in King B liquid media for $48-72 \mathrm{~h}$ at $30^{\circ} \mathrm{C}$, then pipetted onto four spots on solid assay plates containing $0.2 \mathrm{X}$ King $\mathrm{B}$ with CAS. Assay plates were incubated for 7 days at $30^{\circ} \mathrm{C}$, then the orange halos were measured. Isolates that produced particularly large halos were redone with one central spot per plate in triplicate.

\section{Phosphate Solubilization}

Assessment methods for phosphate solubilization were adapted from Ambrosini and Passaglia (2017) using GY/tricalcium phosphate solid medium. GY solid growth medium was prepared using glucose, yeast extract, and $1.5 \%$ agar, then while molten sterile solutions of $\mathrm{K}_{2} \mathrm{HPO}_{4}$ and $\mathrm{CaCl}_{2}$ were added just before pouring. The addition of these two solutions causes insoluble calcium phosphate to precipitate, making the medium cloudy.

21 Bacterial isolates were cultured in King B liquid media for $48-72 \mathrm{~h} 30^{\circ} \mathrm{C}$, then pipetted onto four spots on $\mathrm{GY} /$ tricalcium phosphate solid medium. Plates were incubated for 7 days at $30^{\circ} \mathrm{C}$ then observed for growth and zones of clearing.

\section{Fungal Biocontrol}

Fungal biocontrol assays were performed on tryptic soy agar (TSA) (BBL, Difco, Beckton Dickenson, Franklin Lakes, NJ) plates. Bacterial isolates were cultured in King B liquid media for $48-72 \mathrm{~h}$ before inoculating assay plates. Fungal samples were prepared by suspending stock isolates into sterile water until an optical density at $600 \mathrm{~nm}\left(\mathrm{OD}_{600}\right)$ of 0.1 was reached. A sterile 
swab was used to streak lawns of fungal suspension on TSA plates, then bacterial samples were pipetted onto 4 spots on the plate. Plates were allowed to grow for 7 days then observed for interactions. 15 bacterial isolates were assayed for biocontrol capability against 4 fungal isolates.

\section{Indole Production}

Twenty-one bacterial isolates were grown in King B liquid media supplemented with $2.5 \mathrm{mM}$ tryptophan. IAA production is determined by a spectrophotometric described in Ambrosini and Passaglia (2017), which uses Salkowski's reagent, containing $0.012 \mathrm{~g} / \mathrm{ml} \mathrm{FeCL}_{3}$ and $7.75 \mathrm{M} \mathrm{H}_{2} \mathrm{SO}_{4}$ to react with indoles present in the culture solution.

Liquid cultures were incubated for $48-72 \mathrm{~h}$ at $30^{\circ} \mathrm{C}$. Aliquots were taken to measure the $\mathrm{OD}_{600}$ of the culture, then centrifuged for $10 \mathrm{~min}$ at $5,400 \times \mathrm{g}$. The supernatant was pipetted off, mixed with Salkowski's reagent, then allowed to incubate at room temperature in the dark for $30 \mathrm{~min}$. Samples were run in triplicate through a spectrophotometer at $550 \mathrm{~nm}$ with a set of IAA standards ranging from 0 to $250 \mu \mathrm{g} / \mathrm{ml}$. Sample IAA concentrations calculated from the standard curve were normalized to the measured $\mathrm{OD}_{600}$ of the sample to express the amount of indole produced relative to the final concentration of bacteria.

\section{ACC Deaminase Activity}

The ACC deaminase activity assay uses an indirect method described in Ambrosini and Passaglia (2017). Bacteria are grown on Dworkin and Foster (DF) salts solid media, containing $2 \%$ agar, $2 \mathrm{~g} / \mathrm{L}$ glucose, $2 \mathrm{~g} / \mathrm{L}$ gluconic acid, $4 \mathrm{~g} / \mathrm{L}$ $\mathrm{K}_{2} \mathrm{HPO}_{4}, 6 \mathrm{~g} / \mathrm{L} \quad \mathrm{Na}_{2} \mathrm{HPO}_{4}, 0.2 \mathrm{~g} / \mathrm{L} \quad \mathrm{MgSO}_{4} .7 \mathrm{H}_{2} \mathrm{O}, 2 \mathrm{~g} / \mathrm{L}$ citric acid, $1 \mathrm{mg} / \mathrm{L} \quad \mathrm{FeSO}_{4} .7 \mathrm{H}_{2} \mathrm{O}, \quad 0.01 \mathrm{mg} / \mathrm{L} \quad \mathrm{H}_{3} \mathrm{BO}_{4}, \quad 0.011 \mathrm{mg} / \mathrm{L}$ $\mathrm{MnSO}_{4} \cdot \mathrm{H}_{2} \mathrm{O}, \quad 0.12 \mathrm{mg} / \mathrm{L} \quad \mathrm{ZnSO}_{4} \cdot 7 \mathrm{H}_{2} \mathrm{O}, \quad$ and $\quad 0.008 \mathrm{mg} / \mathrm{L}$ $\mathrm{CuSO}_{4} \cdot 5 \mathrm{H}_{2} \mathrm{O}$. Each isolate is grown on two plates side by side, on one, an ACC solution is spread over the plate providing a $1 \mathrm{mM}$ concentration of ACC, providing the only source of nitrogen. The other plate is left as a nitrogen free control.

21 Bacterial isolates were cultured in King B liquid media for $48-72 \mathrm{~h} 30^{\circ} \mathrm{C}$. Aliquots were centrifuged at 5,400 $\times \mathrm{g}$ for $10 \mathrm{~min}$, the spent media pipetted off, and the bacteria resuspended in $0.85 \%$ saline. This rinse step was repeated 3 times, then the final resuspension pipetted onto three spots on each plate containing DF salts solid medium with or without ACC. Plates were placed in an incubator at $30^{\circ} \mathrm{C}$ for 7 days.

\section{RESULTS}

From the previously isolated microbiome samples from the Veggie crop production system (Khodadad et al., 2020, 21 bacteria were identified (materials and methods for full list) that were readily culturable under general conditions $\left(30^{\circ} \mathrm{C}\right.$ on King B solid media) and remained viable in freezer stocks. Also selected from these previous microbiome studies were 4 fungal species to be used in the antifungal assessment. These samples were isolated from leaf tissue, root tissue, or from the root substrate of the spaceflight Veggie system and are therefore likely candidates to have derived from seedborne endophytic populations.

\section{Siderophore Production}

Siderophores are heavily involved in iron uptake and in doing so can provide effective competition for nutrient resources. Excess iron taken up by PGPB can then be passed off to host plants to improve plant performance. CAS was used to determine the presence of siderphores in culture. This dye solution forms a blue dye complex consisting of chrome azurol S, iron (III), and cetrimonium bromide, which turns orange when a strong chelator, such as a siderophore, removes the iron (Ambrosini and Passaglia, 2017). 9 out of 20 tested isolates were able to grow on the media and produce orange halos including; Acinetobacter genomospecies 3, Burkholderia pyrocinnia, Cupriavidus pauculus, Curtobacterium flaccumfaciens, Paenibacillus macerans, Paenibacillus pabuli, Pantoea agglomerans, Pseudomonas fulva, and Ralstonia picketii (Table 1). Of these, the 5 isolates B. pyrocinnia, C. flaccumfaciens, $P$. macerans, $P$. agglomerans, and $R$. picketii exhibit strong siderophore production, producing large halos with diameters ranging from 4.47 to $5.87 \mathrm{~cm}$ (Figure 1A), compared to the other 4 isolates whose diameters ranged from 0.88 to $1.20 \mathrm{~cm}$ (Figure 1B) (Table 1).

\section{Phosphate Solubilization}

Phosphate is a crucial nutrient for plants and bacteria that can easily precipitate out of solution depending on the environmental $\mathrm{pH}$ and geochemical interactions. Certain PGPB are able to solubilize phosphate to assist with uptake by both the bacteria and host plant. In this assay bacteria incapable of solubilizing the calcium phosphate precipitate will be unable to grow, bacteria that are particularly efficient will develop clear halos around the colony (Ambrosini and Passaglia, 2017). Out of 20 isolates, 5 were able to grow including; Bacillus pumilus, B. pyrocinnia, $C$. flaccumfaciens, $P$. macerans, and $P$. agglomerans (Table 1). Clear halos developed around colonies of B. pyrocinnia, $P$. macerans, and $P$. agglomerans (Figure 2A) while the media around $B$. pumilus and $C$. flaccumfaciens remained opaque with no halo (Figure 2B) (Table 1).

\section{Fungal Biocontrol}

PGPB can play a crucial role in plant pathogen defense by providing competition or producing antimicrobial compounds (Compant et al., 2005). Assessments were made using a co-culturing assay examining simultaneous bacterial and fungal growth. Bacterial antifungal properties were classified on a rating scale from 1 to 4 , with 1 being ineffective and 4 being most effective (Figure 3). Bacteria rating a 4 developed clear zones around the colony, i.e., no fungal growth was observed (Figure 3A) while those with a rating of 3 developed with a zone of reduced fungal growth around the colony (Figure 3B). In samples with a rating of 2, bacteria developed with no fungal growth on the colony but with no effects on the surrounding fungal growth (Figure 3C). Finally, bacteria with a rating of 1 showed no 
TABLE 1 | Siderophore production; growth and resulting halo diameter on $0.2 X$ King B/CAS media after 1 week of growth. $N=4$ for halos under $1.5 \mathrm{~cm}, N=3$ for halos over $1.5 \mathrm{~cm}$. Phosphate Solubilization; growth and resulting halo diameter on GY/tricalcium phosphate media after 1 week of growth. $N=4$ for all samples. Indole production; results of spectrophotometric assay for indole production. Concentration of IAA is calculated based on a set of standards, expressed in $\mu \mathrm{g} / \mathrm{mL}$. IAA concentration was normalized to the final $\mathrm{OD}_{600}$ of the culture to account for slow growing bacteria producing low but significant amounts of indole. ACC deaminase; ACC deaminase indirect assay rankings. 1 indicates no ACC deaminase activity, 2 indicates mild ACC deaminase activity, 3 indicates strong ACC deaminase activity.

\begin{tabular}{|c|c|c|c|c|c|c|c|}
\hline \multirow[t]{3}{*}{ Species } & \multirow{3}{*}{$\begin{array}{c}\begin{array}{c}\text { Siderophore } \\
\text { production }\end{array} \\
\text { Growth (+/-) } \\
\begin{array}{c}\text { Halo diameter } \\
\text { (cm) }\end{array}\end{array}$} & \multicolumn{3}{|c|}{ Phosphate solubilization } & \multicolumn{2}{|c|}{ Indole production } & \multirow{3}{*}{$\begin{array}{c}\text { ACC deaminase } \\
\text { Ranking }\end{array}$} \\
\hline & & Growth (+/-) & Halo (+/-) & Halo diameter & $(\mathrm{IAA})(\mu \mathrm{g} / \mathrm{ml})$ & $($ IAA)/OD 600 & \\
\hline & & & & $(\mathrm{cm})$ & & & \\
\hline A. genomospecies 3 & $+; 1.20 \pm 0.07$ & - & - & - & $18.46 \pm 0.13$ & $36.55 \pm 0.25$ & 3 \\
\hline B. altitudinis & - & - & - & - & $13.08 \pm 0.42$ & $27.47 \pm 0.88$ & 3 \\
\hline B. amyloliquefaciens & - & - & - & - & $15.85 \pm 0.58$ & $53.92 \pm 1.98$ & 3 \\
\hline B. pseudomycoides & - & + & - & $0.30 \pm 0.00$ & $25.09 \pm 0.13$ & $53.85 \pm 0.27$ & $x$ \\
\hline B. pumilus & - & - & - & - & $11.10 \pm 0.25$ & $31.71 \pm 0.72$ & $x$ \\
\hline B. subtilis & - & - & - & - & $26.66 \pm 0.75$ & $84.64 \pm 2.39$ & 3 \\
\hline B. pyrocinnia & $+; 5.87 \pm 0.45$ & + & + & $1.08 \pm 0.19$ & $10.74 \pm 0.38$ & $12.82 \pm 0.45$ & 2 \\
\hline C. pauculus & $+; 0.88 \pm 0.08$ & - & - & - & $15.62 \pm 0.56$ & $20.68 \pm 0.75$ & 3 \\
\hline C. flaccumfaciens & $+; 4.47 \pm 0.24$ & + & - & $0.38 \pm 0.04$ & $64.61 \pm 0.56$ & $203.82 \pm 1.78$ & 1 \\
\hline C. pusillum & - & - & - & - & $17.65 \pm 0.63$ & $52.84 \pm 1.90$ & 1 \\
\hline L. aquatica & - & - & - & - & $15.50 \pm 0.55$ & $22.96 \pm 0.82$ & 1 \\
\hline M. rhodinium & - & - & - & - & $10.65 \pm 0.13$ & $64.55 \pm 0.77$ & 1 \\
\hline M. marytipicum & - & - & - & - & $21.86 \pm 0.13$ & $31.97 \pm 0.19$ & 1 \\
\hline P. macerans & $+; 4.60 \pm 0.47$ & + & + & $0.53 \pm 0.08$ & $22.40 \pm 0.46$ & $263.56 \pm 5.38$ & 1 \\
\hline P. pabuli & $+; 0.90 \pm 0.07$ & - & - & - & $2.58 \pm 0.25$ & $2.98 \pm 0.29$ & 3 \\
\hline P. agglomerans & $+; 4.83 \pm 0.48$ & + & + & $0.85 \pm 0.09$ & $118.13 \pm 14.85$ & $309.23 \pm 38.96$ & 3 \\
\hline$P$. yeeii & - & - & - & - & $9.75 \pm 0.46$ & $19.31 \pm 0.91$ & $x$ \\
\hline P. fulva & $+; 1.05 \pm 0.18$ & - & - & - & $35.41 \pm 0.91$ & $319.02 \pm 8.24$ & 1 \\
\hline R. picketii & $+; 5.80 \pm 0.08$ & - & - & - & $11.64 \pm 0.34$ & $12.47 \pm 0.36$ & 3 \\
\hline S. multivorum & - & - & - & - & $45.92 \pm 0.56$ & $110.64 \pm 1.36$ & 3 \\
\hline S. rhizophila & - & - & - & - & $17.83 \pm 0.83$ & $44.13 \pm 2.06$ & $x$ \\
\hline
\end{tabular}

A

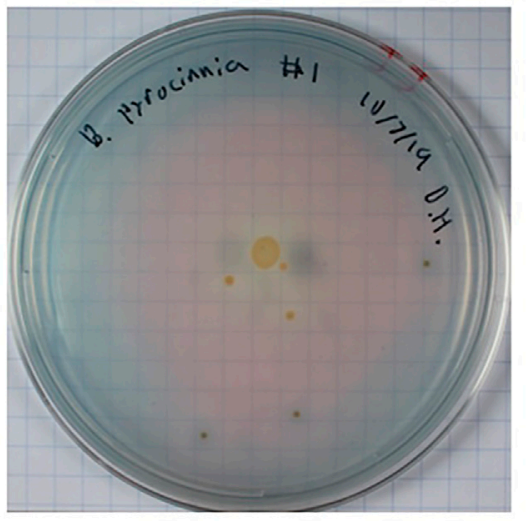

B

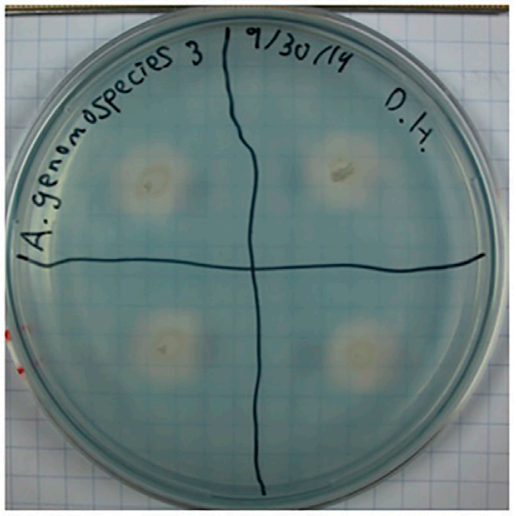

FIGURE 1 | Growth of bacterial isolates on 0.2X King B/CAS assay plates showing examples of (A) a "strong" siderophore producer, Burkholderia pyrrocinia, and (B) a "weak" siderophore producer, Acinetobacter genomospecies 3. Orange/yellow zones indicate removal of iron from the CAS dye complex.

observable impacts on fungal growth on the plate or the colony itself (Figure 3D).

The assessment for each combination of bacteria and fungi is described in Table 2. More than half of the combinations (38/60) were given a rating of 2 against the fungal species Fusarium anthophilum, Aspergillus sydowii, Aspergillus ustus, and
Emericella parvathecia. Only 5/60 combinations were given rating 1 against the fungi, three of them paired against $F$. anthophilum; Leifsonia aquatica, Methylobacterium rhodinum, and $P$. agglomerans, as well as $M$. rhodinum paired against $A$. sydowii and E. parvathecia. 13/60 combinations were given rating 3, most notable being Bacillus amyloliquefaciens causing 
A

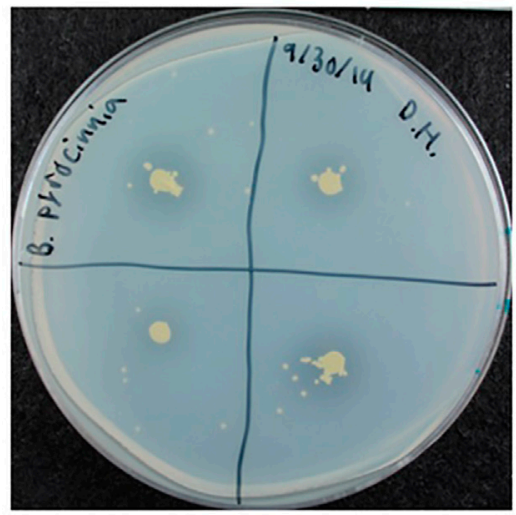

B

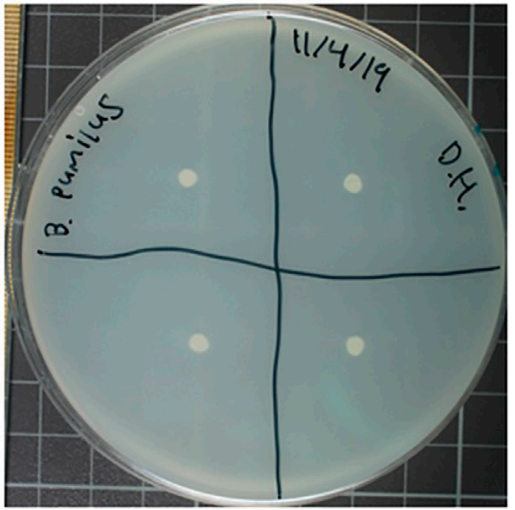

FIGURE 2 | Growth of bacterial isolates on GY/tricalcium phosphate assay plates showing (A) Burkholderia pyrrocinia, capable of developing clear zones around colonies, and (B) Bacillus pumilus, capable of growing on insoluble phosphate but unable to develop clear zones. Growth and/or development of clear zones indicate ability to solubilize calcium phosphate.
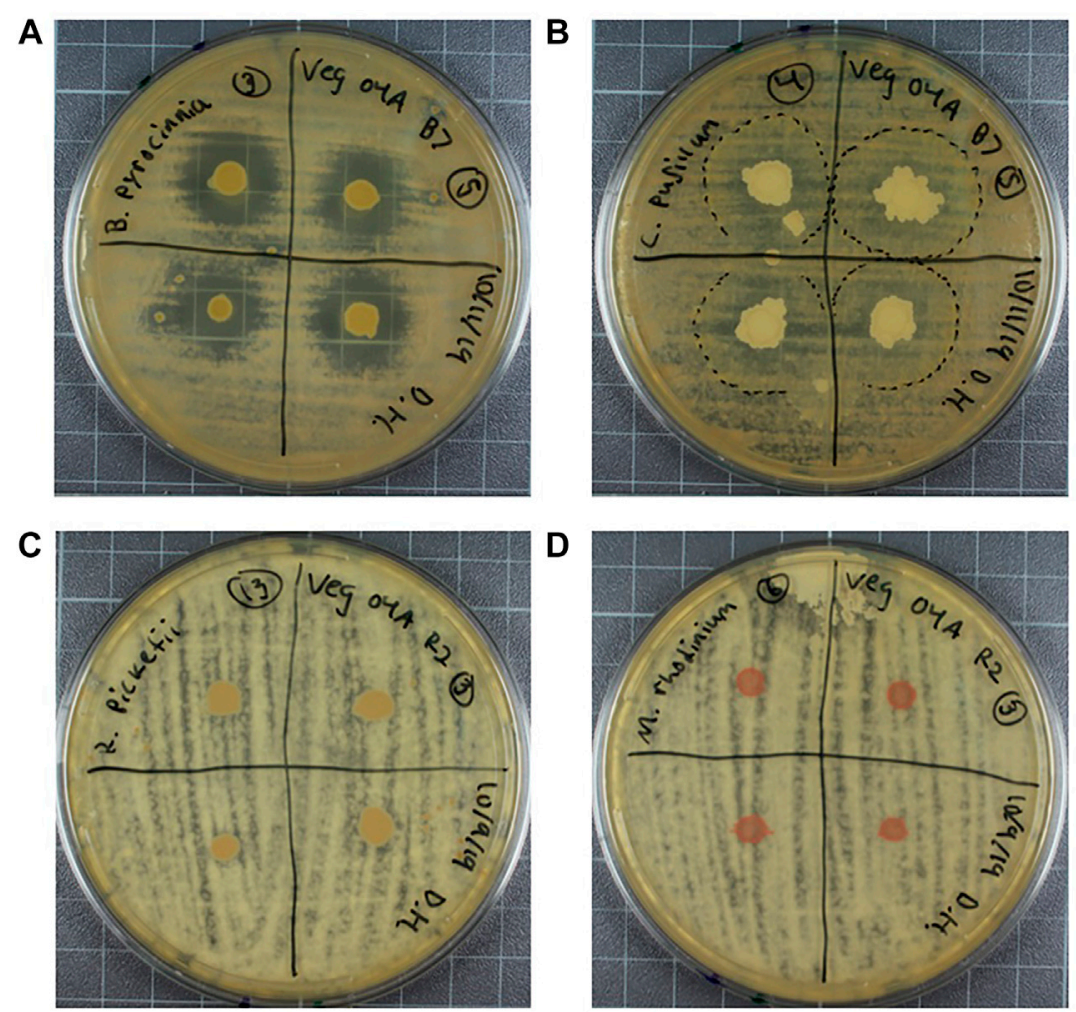

FIGURE 3 | Antifungal assay plates showing examples of (A) Rating 4 growth of Burkholderia pyrrocinia on Emericella parvathecia, (B) Rating 3 growth of Curtobacterium pusillum on Emericella parvathecia, (C) Rating 2 growth of Ralstonia picketii on Aspergillus sydowii and (D) Rating 1 growth of Methylobacterium rhodinum on Aspergillus sydowii.

decreased growth effects on all 4 fungal species, and B. pumilus causing decreased growth effects on all except $F$. anthophilum. Other rating 3 combinations include: Curtobacterium pusillum against $A$. sydowii and E. parvathecia; B. pyrocinnia, P. fulva, and
Stenotrophomonas rhizophila against A. ustus; and Bacillus pseudomycoides against $A$. sydowii. The 4 remaining combinations were given a rating of $4 ; B$. pyrocinnia exhibited cleared zones with $A$. ustus and E. parvathecia, and $B$. 
TABLE 2|Antifungal assessment results of bacterial isolates on four fungal isolates. Rating 4 exhibits zones of no fungal growth around the bacterial colony. Rating 3 bacteria have zones of reduced fungal growth around the colony. Rating 2 bacteria only prevent fungal growth within the bacterial colony. Rating 1 bacteria are unable to prevent fungal growth in or around the bacterial colony.

\begin{tabular}{|c|c|c|c|c|}
\hline Species & F. anthophilum & A. sydowii & A. ustus & E. paravathecia \\
\hline A. genomospecies 3 & 2 & 2 & 3 & 2 \\
\hline B. amyloliquefaciens & 3 & 3 & 3 & 3 \\
\hline B. Pseudomycoides & 2 & 3 & 4 & 4 \\
\hline B. pimilis & 2 & 3 & 3 & 3 \\
\hline B. pyrocinnia & 2 & 4 & 3 & 4 \\
\hline C. pusillum & 2 & 3 & 2 & 3 \\
\hline L. aquatica & 1 & 2 & 2 & 2 \\
\hline M. rhodinum & 1 & 1 & 2 & 1 \\
\hline M. marytipicum & 2 & 2 & 2 & 2 \\
\hline P. pabuli & 2 & 2 & 2 & 2 \\
\hline P. agglomerans & 1 & 2 & 2 & 2 \\
\hline P. yeeii & 2 & 2 & 2 & 2 \\
\hline P. fulva & 2 & 2 & 3 & 2 \\
\hline R. picketii & 2 & 2 & 2 & 2 \\
\hline S. rhizophila & 2 & 2 & 3 & 2 \\
\hline
\end{tabular}
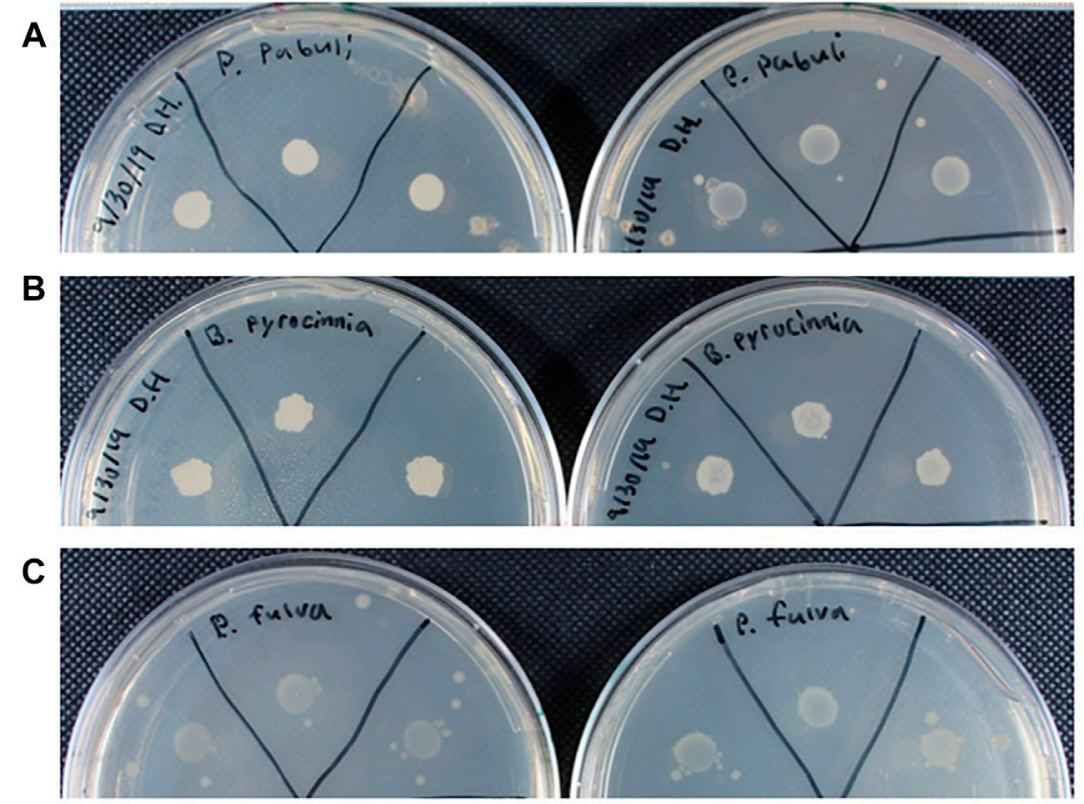

FIGURE 4 | Growth of bacteria on DF salts medium with $1 \mathrm{mM} \mathrm{ACC} \mathrm{(left)} \mathrm{and} \mathrm{nitrogen} \mathrm{free} \mathrm{(right).} \mathrm{(A)} \mathrm{Example} \mathrm{of} \mathrm{rating} 3$ growth, $P$. pabuli, showing improved growth in the presence of ACC. (B) Example of rating 2 growth, B. pyrocinnia, showing mildly improved growth in the presence of ACC. (C) example of rating 1 growth, $P$. fulva, showing no improved growth in the presence of ACC.

pseudomycoides exhibited cleared zones on A. sydowii and E. parvathecia.

\section{Indole Production}

Bacterial production of IAA, the most common auxin, can improve plant growth by stimulating root and stem elongation. A spectrophotometric assay (Ambrosini and Passaglia, 2017) determined that most bacterial isolates produced some amount of indole, typically in the $10-25 \mu \mathrm{g} / \mathrm{ml}$ range, though $P$. pabuli produced a particularly low amount of indole that may be false due to instrument sensitivity (Table 1). Others produced a particularly high amount of indole, such as $P$. agglomaerans. To account for cultures with low cell density at time of analysis, calculated indole measurements were normalized to the $\mathrm{OD}_{600}$ of the culture, creating ratio of indole concentration to relative cell abundance. This revealed that C. flaccumfaciens, $P$. fulva, Sphingobacterium multivorum, and $P$. macerans produce more significant amounts of indole than the raw data would indicate. This 
normalization also confirms that other bacteria, such as $P$. pabuli and $R$. picketii, do not produce notable amounts of indole.

\section{ACC Deaminase Activity}

The plant hormone ethylene is heavily involved in plant stress response and is responsible for many of the resulting phenotypes of stress conditions. The precursor molecule to ethylene, ACC, can be used as a nitrogen source by PGPB, and in doing so, the bacteria limits the amount of ethylene produced. An indirect assay was used to detect ACC deaminase based on growth patterns (Ambrosini and Passaglia, 2017). Isolates were rated based on differential growth between plates with and without ACC on a scale of $1-3$, with 3 indicating improved growth on plates with ACC (Figure 4A), 2 indicating mildly improved growth (Figure 4B), and a 1 indicating poor growth on both plates (Figure 4C) Bacteria that produce ACC deaminase were able to grow on the plate with ACC and poorly on the plate without ACC, whereas bacteria that do not produce ACC deaminase grew poorly on both. Bacteria that showed growth unlike these, such as growing well on both, or better on the ACC free plate, are described as indeterminant. These bacteria are likely capable of nitrogen fixation and therefore do not depend on nitrogen in the growth media. Of the 21 isolates examined, 9 species were given a rating of 3,1 species was given a rating of 2, 4 species a rating of 1 , and the remaining isolates were classified and indeterminant (Table 1).

\section{DISCUSSION}

The spaceflight environment has proven to be stressful to plants, yet long-term operations in deep space depend on successful plant growth for supplemental life support, food production, and psychological benefits. The isolation and detection of PGPB with spaceflight history provides an opportunity to improve plant growth through the development of a curated microbiome for the growth of plants aboard the ISS, on the Moon, or another planet. Using several biochemical and phenotypic assessments of bacteria isolated from the Veggie crop production system, we have confirmed the potential for several PGPB to exist in conjunction with plants grown on the ISS. However it remains to be seen if these bacteria are indeed capable of encouraging plant growth within the spaceflight environment. Of the 21 bacterial isolates, 17 were shown to be capable of at least one plant beneficial function, though most performed 2 to 3 of these functions. Of those appeared to generate indole, further studies will need to confirm the presence of IAA, especially those that did not exhibit other plant growth promoting functions, due to the assay used being general for all indoles.

These assessments provide a collection of culturable, space viable $\mathrm{PGPB}$ for the selective application to space food production systems. The selection of microorganisms for our planned community could be made smaller and more manageable by the selection of "generalist" PGPB, i.e. those that perform two or more of the plant-growth promoting functions evaluated herein. A potential minimal microbiome from this set of isolates would consist of just $P$. agglomerans, and $B$. pyrocinnia, both capable of phosphate solubilization, siderophore production, and ACC deamination. $P$. agglomerans also produces indoles while B. pyrocinnia provides antifungal capabilities.

Both species have been previously studied for plant growth promotion. Studies have shown that certain strains of $P$. agglomerans have nitrogen fixing capabilities, produce not only IAA, but also the phytohormones abscisic acid, gibberellic acid, and cytokinins (Feng et al., 2006). Inoculations of rice seedlings with the species increases overall growth rate and improved nutrient uptake preventing malnutrition stress (Feng et al., 2006; Jiang et al., 2015) other studies show that $P$. agglomerans also has the ability to reduce heavy metal toxicity (Luziatelli et al., 2020) and provide biocontrol against the plant pathogen Ralstonia solanacearum (Singh et al., 2020). B. pyrocinnia is a member of the Burkholderia cepacia complex and has been investigated for its biocontrol potential against plant pathogen Rhizoctonia solani via production of the antibiotic pyrrolnitrin (Schmidt et al., 2009) and studies on its siderophores have shown the ability to improve seed germination, plant size and fruit size (Min et al., 2019).

An inoculated microbiome can also be tailored for specific functions. ISRU approaches using regolith as a plant growth substrate on Mars will need to prioritize the acquisition of mineral nutrients, so the selection of microbes may be expanded to include C. flaccumfaciens and P. macerans, both of which solubilize phosphate and produce siderophores. Hydroponic systems would not require the highly active nutrient scavenging bacteria, but inoculation with indole producing, ethylene reducing, and pathogen mediating bacteria can help increase biomass and yield in hydroponic systems (Lee and Lee, 2015; Paradiso et al., 2017). Thus, including indole producing bacteria such as $P$. fulva and $P$. macerans, ACC deaminating bacteria such as $P$. pabuli and $R$. picketii, and antifungal bacteria such as $B$. pseudomycoides and $B$. amyloliquefaciens would improve the robustness and efficiency of the system.

Ultimately, the selection of the most appropriate PGPB will be determined by the location of Lunar and Martian colony sites, as well as the method of plant growth. ISRU approaches will have to be tailored not just to the planetary body, but also the specific colony site as locations will vary in mineralogy, which will also require the development of site specific regolith simulants important for research in these systems (Ramkissoon et al., 2019; Fackrell et al., 2021). The use of siderophore producing or phosphate solubilizing bacteria will be dependent on the amount of insoluble nutrients available in the on-site substrate, as well as what interactions applied fertilizers may have with the geologic material.

Compounds contained in on-site regolith may also create a need for plant growth promoting functions not investigated here, such as remediation of perchlorate compounds found on the Martian surface (Hecht et al., 2009; Navarro-González et al., 2010). These compounds have the potential to bioaccumulate in plant tissues (Sanchez et al., 2005) and 
be toxic to Martian colonists (Lawrence et al., 2000), but can also be a source of breathable oxygen when degraded by perchlorate reducing bacteria (Carlström et al., 2015).

Before implementing these bacteria into food production systems, each species will need to be validated for use. Further testing should include in planta studies to confirm that the strains investigated are plant growth promoting. Certain species investigated, such as C. flaccumfaciens have variants that are plant growth promoters (Bulgari et al., 2014) and others that cause disease such as bacterial wilt (Osdaghi et al., 2020). Species of interest for food production systems will also need to be screened for their potential as human pathogens, whether opportunistic or otherwise to ensure crew safety. However, it should be noted that the strains analyzed here are already present in the plant growth systems being tended to by astronauts on the ISS.

As research into BLSS continues, further investigation of PGPB will be crucial. The ISS has already shown that current sterilization and sanitization practices have been shown to be ineffective at preventing opportunistic microorganisms from infecting plants, and the stress effects caused by the space environment can be mitigated to improve plant growth and yield. As crops are selected for space food production systems,

\section{REFERENCES}

Ambrosini, A., and Passaglia, L. M. P. (2017). Plant Growth-Promoting Bacteria (PGPB): Isolation and Screening of PGP Activities. Curr. Protoc. Plant Biol. 2, 190-209. doi:10.1002/pb.20054

Avila-Herrera, A., Thissen, J., Urbaniak, C., Be, N. A., Smith, D. J., Karouia, F., et al. (2020). Crewmember Microbiome May Influence Microbial Composition of ISS Habitable Surfaces. PLoS One 15, e0231838. doi:10.1371/ journal.pone.0231838

Blake, D. F., Morris, R. V., Kocurek, G., Morrison, S. M., Downs, R. T., Bish, D., et al. (2013). Curiosity at Gale Crater, Mars: Characterization and Analysis of the Rocknest Sand Shadow. Science 341, 1239505. doi:10.1126/science.1239505

Bugbee, B. G., and Salisbury, F. B. (2015). Controlled Environment Crop Production: Hydroponic vs. Lunar Regolith. Lunar Regolith 107-129. doi:10.2134/1989.lunarbaseagriculture.c8

Carlström, C. I., Loutey, D., Bauer, S., Clark, I. C., Rohde, R. A., Iavarone, A. T., et al. (2015). (Per)Chlorate-Reducing Bacteria Can Utilize Aerobic and Anaerobic Pathways of Aromatic Degradation with (Per)Chlorate as an Electron Acceptor. MBio 6, e02287-14. doi:10.1128/mBio.02287-14

Checinska Sielaff, A., Urbaniak, C., Mohan, G. B. M., Stepanov, V. G., Tran, Q., Wood, J. M., et al. (2019). Characterization of the Total and Viable Bacterial and Fungal Communities Associated with the International Space Station Surfaces. Microbiome 7, 50. doi:10.1186/s40168-019-0666-x

Compant, S., Duffy, B., Nowak, J., Cle'ment, C., and Barka, E. A. (2005). Use of Plant Growth-Promoting Bacteria for Biocontrol of Plant Diseases: Principles, Mechanisms of Action, and Future Prospects. Appl. Environ. Microbiol. 71, 4951-4959. doi:10.1128/AEM.71.9.4951-4959.2005

Cooper, M. R. (2013). Initial Nutritional Quality of ISS Space Food Provisions NASA HRP Investigator's Workshop. TX: Galveston.

Eichler, A., Hadland, N., Pickett, D., Masaitis, D., Handy, D., Perez, A., et al. (2021). Challenging the Agricultural Viability of Martian Regolith Simulants. Icarus 354, 114022. doi:10.1016/j.icarus.2020.114022

Fackrell, L. E., Schroeder, P. A., Thompson, A., Stockstill-Cahill, K., and Hibbitts, C. A. (2021). Development of Martian Regolith and Bedrock Simulants: Potential and Limitations of Martian Regolith as an In-Situ Resource. Icarus 354, 114055. doi:10.1016/j.icarus.2020.114055

Feng, Y., Shen, D., and Song, W. (2006). Rice Endophyte Pantoea Agglomerans YS19 Promotes Host Plant Growth and Affects Allocations of Host and sites are selected for colonization on the Moon and Mars, this work will go towards providing the foundation for developing robust and sustainable agricultural systems.

\section{DATA AVAILABILITY STATEMENT}

The original contributions presented in the study are included in the article/Supplementary Material, further inquiries can be directed to the corresponding author.

\section{AUTHOR CONTRIBUTIONS}

DH contributed the bulk of experimental design, performed experiments and data analysis and was primary writer. $\mathrm{MH}$, $\mathrm{AD}$ and $\mathrm{AR}$ contributed equally to determining the scope, experimental design, and were secondary writers. GM is the point of contact for Veggie and helped provide access to key isolates and consulted on experimental design. AP consulted on experimental design, determining the scope of the manuscript, and was a secondary writer.

Photosynthates. J. Appl. Microbiol. 100, 938-945. doi:10.1111/j.13652672.2006.02843.x

Franche, C., Lindström, K., and Elmerich, C. (2009). Nitrogen-fixing Bacteria Associated with Leguminous and Non-leguminous Plants. Plant Soil 321, 35-59. doi:10.1007/s11104-008-9833-8

Gamalero, E., and Glick, B. R. (2015). Bacterial Modulation of Plant Ethylene Levels. Plant Physiol. 169, 13-22. doi:10.1104/pp.15.00284

Hecht, M. H., Kounaves, S. P., Quinn, R. C., West, S. J., Young, S. M. M., Ming, D. W., et al. (2009). Detection of Perchlorate and the Soluble Chemistry of Martian Soil at the Phoenix Lander Site. Science 325, 64-67. doi:10.1126/ science. 1172466

Jiang, J., Wu, S., Wang, J., and Feng, Y. (2015). AHL-type Quorum Sensing and its Regulation on Symplasmata Formation in Pantoea agglomerans YS19. J. Basic Microbiol. 55, 607-616. doi:10.1002/jobm.201400472

Khodadad, C. L. M., Hummerick, M. E., Spencer, L. E., Dixit, A. R., Richards, J. T., Romeyn, M. W., et al. (2020). Microbiological and Nutritional Analysis of Lettuce Crops Grown on the International Space Station. Front. Plant Sci. 11, 1-15. doi:10.3389/fpls.2020.00199

Lawrence, J. E., Lamm, S. H., Pino, S., Richman, K., and Braverman, L. E. (2000). The Effect of Short-Term Low-Dose Perchlorate on Various Aspects of Thyroid Function. Thyroid 10, 659-663. doi:10.1089/10507250050137734

Lee, S., and Lee, J. (2015). Beneficial Bacteria and Fungi in Hydroponic Systems: Types and Characteristics of Hydroponic Food Production Methods. Scientia Horticulturae 195, 206-215. doi:10.1016/j.scienta.2015.09.011

Ludwig-Müller, J. (2015). Bacteria and Fungi Controlling Plant Growth by Manipulating Auxin: Balance between Development and Defense. J. Plant Physiol. 172, 4-12. doi:10.1016/j.jplph.2014.01.002

Luziatelli, F., Ficca, A. G., Cardarelli, M., Melini, F., Cavalieri, A., and Ruzzi, M. (2020). Genome Sequencing of Pantoea Agglomerans C1 Provides Insights into Molecular and Genetic Mechanisms of Plant Growth-Promotion and Tolerance to Heavy Metals. Microorganisms 8, 153-217. doi:10.3390/ microorganisms 8020153

Massa, G. D., Dufour, N. F., Carver, J. A., Hummerick, M. E., Wheeler, R. M., Morrow, R. C., et al. (2017a). VEG-01: Veggie Hardware Validation Testing on the International Space Station. Open Agric. 2. doi:10.1515/opag-2017-0003

Massa, G. D., Newsham, G., Hummerick, M. E., Morrow, R. C., and Wheeler, R. M. (2017b). Plant Pillow Preparation for the Veggie Plant Growth System on the International Space Station. Gravit. Sp. Res. 5, 24-34. doi:10.2478/gsr-20170002 
Mauerer, M., Schubert, D., Zabel, P., Bamsey, M., Kohlberg, E., and Mengedoht, D. (2016). Initial Survey on Fresh Fruit and Vegetable Preferences of Neumayer Station Crew Members: Input to Crop Selection and Psychological Benefits of Space-Based Plant Production Systems. Open Agric. 1, 179-188. doi:10.1515/ opag-2016-0023

Min, L. J., Wu, X. Q., Li, D. W., Chen, K., Guo, L., and Ye, J. R. (2019). Burkholderia Pyrrocinia JK - SH007 Enhanced Seed Germination, Cucumber Seedling Growth and Tomato Fruit via Catecholate - Siderophore - Mediation. Intl. J. Agric. Biol.895, 779-786. doi:10.17957/IJAB/15.1130

Navarro-González, R., Vargas, E., de la Rosa, J., Raga, A. C., and McKay, C. P. (2010). Reanalysis of the Viking Results Suggests Perchlorate and Organics at Midlatitudes on Mars. J. Geophys. Res. 115, E12010. doi:10.1029/2010JE003599

Odeh, R., and Guy, C. L. (2017). Gardening for Therapeutic People-Plant Interactions During Long-Duration Space Missions. Open Agric. 2, 1-13. doi:10.1515/opag-2017-0001

Paradiso, R., Arena, C., De Micco, V., Giordano, M., Aronne, G., and De Pascale, S. (2017). Changes in Leaf Anatomical Traits Enhanced Photosynthetic Activity of Soybean Grown in Hydroponics with Plant Growth-Promoting Microorganisms. Front. Plant Sci. 8, 674. doi:10.3389/fpls.2017.00674

Pitzschke, A. (2016). Developmental Peculiarities and Seed-Borne Endophytes in Quinoa: Omnipresent, Robust Bacilli Contribute to Plant Fitness. Front. Microbiol. 7, 2. doi:10.3389/fmicb.2016.00002

Ramkissoon, N. K., Pearson, V. K., Schwenzer, S. P., Schröder, C., Kirnbauer, T., Wood, D., et al. (2019). New Simulants for Martian Regolith: Controlling Iron Variability. Planet. Space Sci. 179, 104722. doi:10.1016/j.pss.2019.104722

Ravel, C., Michalakis, Y., and Charmet, G. (1997). The Effect of Imperfect Transmission on the Frequency of Mutualistic Seed-Borne Endophytes in Natural Populations of Grasses. Oikos 80, 18. doi:10.2307/3546511

Rodríguez, H., Fraga, R., Gonzalez, T., and Bashan, Y. (2006). Genetics of Phosphate Solubilization and its Potential Applications for Improving Plant Growth-Promoting Bacteria. Plant Soil 287, 15-21. doi:10.1007/s11104-006-9056-9

Sanchez, C. A., Krieger, R. I., Khandaker, N., Moore, R. C., Holts, K. C., and Neidel, L. L. (2005). Accumulation and Perchlorate Exposure Potential of Lettuce
Produced in the Lower Colorado River Region. J. Agric. Food Chem. 53, 5479-5486. doi:10.1021/jf050380d

Scavino, A. F., and Pedraza, R. O. (2013). "The Role of Siderophores in Plant Growth-Promoting Bacteria," in Bacteria in Agrobiology: Crop Productivity. Editors D. K. Maheshwari, M. Saraf, and A. Aeron (Berlin, Heidelberg: Springer), 265-285. doi:10.1007/978-3-642-37241-4_11

Schmidt, S., Blom, J. F., Pernthaler, J., Berg, G., Baldwin, A., Mahenthiralingam, E., et al. (2009). Production of the Antifungal Compound Pyrrolnitrin Is Quorum Sensing-Regulated in Members of the Burkholderia Cepaciacomplex. Environ. Microbiol. 11, 1422-1437. doi:10.1111/j.1462-2920.2009.01870.x

Singh, D., Yadav, D. K., and Fatima, F. (2020). Characterization and Genetic Diversity of Pantoea Agglomerans Isolates Having Dual Potentiality to Suppress Growth of Ralstonia Solanacearum and Plant Growth Promoting Ability. Indian Phytopathology 73, 643-653. doi:10.1007/ s42360-020-00268-1

Conflict of Interest: The authors declare that the research was conducted in the absence of any commercial or financial relationships that could be construed as a potential conflict of interest.

Publisher's Note: All claims expressed in this article are solely those of the authors and do not necessarily represent those of their affiliated organizations or those of the publisher, the editors, and the reviewers. Any product that may be evaluated in this article or claim that may be made by its manufacturer is not guaranteed or endorsed by the publisher.

Copyright (C) 2021 Handy, Hummerick, Dixit, Ruby, Massa and Palmer. This is an open-access article distributed under the terms of the Creative Commons Attribution License (CC BY). The use, distribution or reproduction in other forums is permitted, provided the original author(s) and the copyright owner(s) are credited and that the original publication in this journal is cited, in accordance with accepted academic practice. No use, distribution or reproduction is permitted which does not comply with these terms. 